\title{
Papers
}

\section{Indirect comparison meta-analysis of aspirin therapy after coronary surgery}

Eric Lim, Ziad Ali, Ayyaz Ali, Tom Routledge, Lyn Edmonds, Douglas G Altman, Stephen Large

\begin{abstract}
Objectives To evaluate the efficacy of low and medium dose aspirin therapy after coronary surgery by using an indirect comparison meta-analysis.

Data sources Systematic literature search of Medline, Embase, Cochrane controlled trials register, and trial register sites on the internet.

Study selection Outcome was evaluated by angiography and reported as graft occlusion and rate of events in patients. Trials that did not include aspirin as the sole therapy or did not have a placebo control arm were excluded. Articles were assessed for eligibility and quality and grouped according to dosage. The estimated difference in effect of low and medium dose aspirin on graft occlusion was obtained by combining the estimated log relative risks of low dose with placebo and medium dose with placebo.

Results For graft occlusion, the medium dose trials yielded a relative risk reduction of $45 \%$ compared with $26 \%$ for the low dose trials. The greater effect in the medium dose trials is summarised by a relative risk ratio of $0.74(95 \%$ confidence interval 0.52 to $1.06 ; \mathrm{P}=0.10)$ for graft occlusion and $0.81(0.57$ to $1.16 ; \mathrm{P}=0.25$ ) for events in patients.

Conclusions Medium dose aspirin may more successfully reduce graft occlusion than low dose regimens within the first year after coronary surgery.
\end{abstract}

\section{Introduction}

What do we really know about the effect of treatment with aspirin after coronary artery bypass surgery? In the United Kingdom over 25000 such procedures are performed annually. ${ }^{1}$ Despite the increasing popularity of arterial grafts, the saphenous vein remains widely used and has an estimated occlusion rate of $15-30 \%$ in the first year. ${ }^{2}$

In the past decade, beneficial effects of aspirin on graft patency were established by three meta-analyses that summarised trials from 1979 to $1993{ }^{3-5}$ However, analyses took no account of the wide variation in doses (from $75 \mathrm{mg}$ to $325 \mathrm{mg}$ ), and equivalent efficacy was assumed within this range. As a result, low dose aspirin $(75-150 \mathrm{mg}$ ) is prescribed despite no direct comparisons against medium dose (300-325 mg) regimens.

We evaluated the efficacy of low dose aspirin with medium dose therapy on graft patency after coronary artery surgery using indirect comparison meta-analysis.

\section{Methods \\ Search strategy}

We undertook a systematic literature search of the major bibliographic databases-Medline (1966 to April week 3, 2003) and Embase (1974 to 2003, week 17)-using the following text and thesaurus terms in combination: clinical trial, research design, placebo, random, aspirin, anticoagulant, antithrombotic, platelet aggregation inhibitors, coronary artery bypass, vascular patency, graft occlusion, graft survival. This was performed in conjunction with methodological therapy filters specific to each database (full search details are available from EL). We also searched the Cochrane controlled trials register, the national research register, and trial sites on the internet for additional articles. The reference lists of all relevant studies were reviewed, and consultation was undertaken with senior colleagues and authors of previous trials.

\section{Study selection}

We included all randomised controlled trials that evaluated the efficacy of medium or low dose aspirin in preventing occlusion of vein grafts. No restrictions were placed on abstracts, conference proceedings, or language. Primary exclusion criteria included a total daily dose of aspirin less than $50 \mathrm{mg}$ or more than $325 \mathrm{mg}$. We also excluded trials that did not include aspirin as sole therapy (to eliminate the effect of other concomitant therapy on vein graft patency) and studies that did not use a placebo control because placebo was the intermediary used for the indirect comparison. A given patient population was only used once: if the same population appeared in other publications, we selected the article that provided the most complete follow up data.

Three investigators independently assessed papers according to the predetermined eligibility criteria, and discordances were resolved by consensus review. Quality of the individual studies was assessed on the basis of randomisation, blind assessment of outcome, and number lost to follow up. The studies in this metaanalysis were grouped according to aspirin dosage; low dose was defined as $50-150 \mathrm{mg}$ daily and medium dose as $300-325 \mathrm{mg}$ daily.

\section{Data abstraction}

All the trials evaluated outcome by angiography and reported it as graft occlusion and event rate in patients. Grafts were considered occluded if the distal anastomosis could not be visualised by angiography. If the origin was occluded, all subsequent distal anastamoses were also considered to be occluded. If angiography was performed on more than one occasion we analysed data recorded closest to one year. An event in a patient was defined as one or more occlusions of a saphenous vein graft. 
Table 1 Participant characteristics of each trial

\begin{tabular}{|c|c|c|c|c|c|c|c|c|}
\hline Trial and regimen & No randomised & $\begin{array}{l}\text { Mean (SD) age } \\
\text { (years) }\end{array}$ & $\begin{array}{l}\text { Men } \\
(\%)\end{array}$ & Smokers (\%) & Hypertensive (\%) & $\begin{array}{l}\text { Cholesterol } \\
(\mathrm{mmol} / \mathrm{l})\end{array}$ & $\begin{array}{l}\text { Time to angiography } \\
\text { (days) }\end{array}$ & $\begin{array}{l}\text { Proportion not receiving } \\
\text { angiography (\%) }\end{array}$ \\
\hline \multicolumn{9}{|l|}{ Gavaghan ${ }^{42}$ : } \\
\hline Aspirin $324 \mathrm{mg}$ & 127 & $56(7)$ & 87 & 65 & 45 & 7.1 & $363^{\star}$ (median) & $8^{*}$ \\
\hline Placebo & 110 & $56(6)$ & 84 & 67 & 39 & 7.0 & $363^{*}$ (median) & $8^{\star}$ \\
\hline \multicolumn{9}{|l|}{ Goldman ${ }^{41}$ : } \\
\hline Aspirin 325 mg & 104 & $59(8)$ & 100 & NA & 47 & 5.9 & $367^{*}$ (median) & $35^{*}$ \\
\hline Placebo & 107 & $58(8)$ & 100 & NA & 53 & 5.7 & $367^{\star}$ (medain) & $35^{\star}$ \\
\hline \multicolumn{9}{|l|}{ Lorenz $^{40}$ : } \\
\hline Aspirin 100 mg & $29 \dagger$ & $55(10)$ & 83 & NA & NA & 6.9 & 131 (mean) & 24 \\
\hline Placebo & $31 \dagger$ & $55(6)$ & 90 & NA & NA & 7.2 & 129 (mean) & 23 \\
\hline \multicolumn{9}{|l|}{ Sanz ${ }^{43}$ : } \\
\hline Aspirin $150 \mathrm{mg}$ & 373 & $57(8)$ & 90 & 65 & 40 & 6.0 & 10 (mean) & $17^{*}$ \\
\hline Placebo & 371 & $56(8)$ & 89 & 68 & 38 & 6.0 & 11 (mean) & $17^{\star}$ \\
\hline \multicolumn{9}{|l|}{ Hockings ${ }^{44}$ : } \\
\hline Aspirin $100 \mathrm{mg}$ & 50 & $60(9)$ & 94 & $\mathrm{~N} / \mathrm{A}$ & 50 & NA & $180^{*}$ (NA) & $27^{*}$ \\
\hline Placebo & 52 & $60(9)$ & 92 & $\mathrm{~N} / \mathrm{A}$ & 31 & NA & $180^{*}(\mathrm{NA})$ & $27^{*}$ \\
\hline
\end{tabular}

NA $=$ not available.

*Value reported for entire study cohort.

†Number of patients reported at end of study.

\section{Statistical methods}

In the absence of randomised trials making head to head comparisons, an indirect comparison is possible using a common comparator. ${ }^{6-10}$ We performed a meta-analysis combining trials of low dose aspirin versus placebo to obtain the estimated relative risk, $\mathrm{RR}_{\mathrm{LP}} \mathrm{A}$ separate meta-analysis of trials comparing medium dose aspirin versus placebo yielded an estimated relative risk, $\mathrm{RR}_{\mathrm{MP}}$. We obtained the estimated difference in effect of low and medium dose aspirin, $\mathrm{RR}_{\mathrm{ML}}$, by combining the two estimated log relative risks as follows:

$\log R R_{M L}=\log R R_{M P}-\log R R_{L P} \operatorname{var}\left(\log R R_{M I}\right)=\operatorname{var}\left(\log R R_{M P}\right)+$ $\operatorname{var}\left(\log R R_{L P}\right)$

where var indicates the square of the standard error (variance). From these values we calculated a 95\% confidence interval for $\operatorname{logRR} \mathrm{RL}_{\mathrm{ML}}$. All values were back transformed to give the estimate of $\mathrm{RR}_{\mathrm{VL}}$ with a $95 \%$ confidence interval. This analysis can be seen as the simplest form of meta-regression ${ }^{11}$ with a single binary trial factor or, equivalently, as an examination of the interaction between treatment effect and dose of aspirin. ${ }^{12}$ We also performed the analysis using odds ratios instead of risk ratios, although we expected differences to be minor as the events are rare.

The statistical analysis of graft patency presents a particular difficulty as patients typically receive several grafts, and it cannot be assumed that grafts within patients act independently. To avoid such cluster sampling error we also analysed graft patency in terms of rates of events in patients. ${ }^{13}$

\section{Results}

\section{Trial flow and trial characteristics}

Of 32 publications identified for review, none were excluded for administering aspirin in doses of less than $50 \mathrm{mg}, 14$ were excluded for administering aspirin in dosages above $325 \mathrm{mg}$ (ranging from $650 \mathrm{mg}$ to $1200 \mathrm{mg}$ a day), ${ }^{14-26}$ seven trials did not have an aspirin only arm, ${ }^{27-33}$ and two did not use placebo control. ${ }^{34}{ }^{35}$ Four further publications were excluded because they were repeat publications with the same data. ${ }^{36-39}$ We identified five published trials as eligible for overview and included them in the meta-analysis. ${ }^{40-44}$ Three trials used low dose aspirin whereas two used medium dose regimens.

Two trials were multicentred ${ }^{41} 43$ and the three others were single institution studies. ${ }^{42}{ }^{44}$ Method of recruitment was explic- itly stated in two trials. ${ }^{41}{ }^{43}$ Exclusion criteria included upper age limit $^{42}{ }^{43}$ and previous or concomitant surgery. ${ }^{41-44}$ Two trials reported standardisation of surgical procedure. ${ }^{40}{ }^{42}$ All trials were blinded and included a placebo control arm. Three trials reported formal randomisation by research coordinating centres or pharmacy ${ }^{41-43}$ In all five trials postoperative aspirin was given within the first 24 hours. Two trials reported independent angiographic analysis of vein graft patency, ${ }^{40}$ and one trial reported further assessment of reliability of angiographic analysis. ${ }^{41}$ Table 1 summarises the baseline participant characteristics within each study arm and between the medium and low arms.

\section{Meta-analysis}

Table 2 shows the rates of graft patency and events in patients for each trial. The pooled relative risk reduction for graft occlusion was $45 \%$ in the medium dose trials $(0.55,95 \%$ confidence interval 0.41 to 0.73 ) compared with $26 \%$ in the low dose trials $(0.74$, 0.60 to 0.91$)$, a relative risk ratio of $0.74(0.52$ to $1.06 ; \mathrm{P}=0.10)$ (figure). However, this analysis is per vein and thus includes patients more than once, so that the results are overprecise. The results for event rates in patients were broadly similar (table 2 , figure) but with a relative risk ratio of $0.81(0.57$ to $1.16 ; \mathrm{P}=0.25)$. When we used odds ratios rather than relative risk the results were similar.

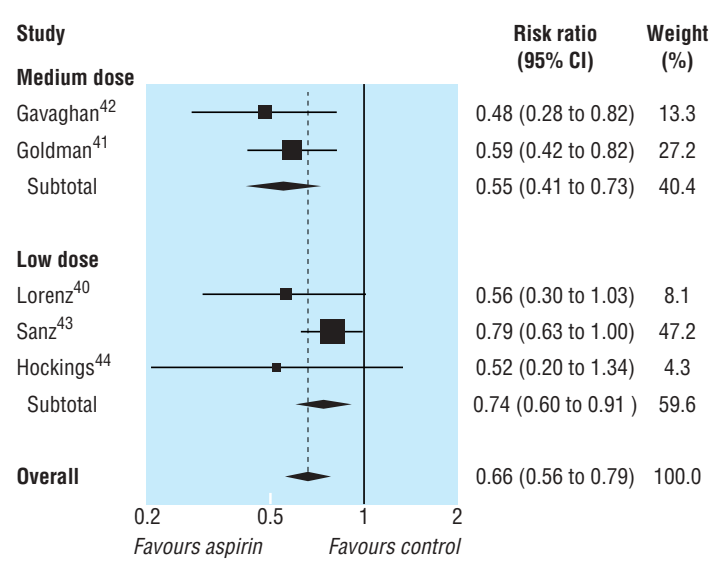

Relative risk of each aspirin regimen compared with placebo for graft occlusion (see table 2 for complete data) 
Table 2 Results of trials of aspirin treatment after coronary surgery

\begin{tabular}{|c|c|c|c|c|c|c|c|c|}
\hline Trial and regimen & $\begin{array}{l}\text { No of distal } \\
\text { anastomosis }\end{array}$ & $\begin{array}{c}\text { No of } \\
\text { occlusions }\end{array}$ & Occlusion rate & $\begin{array}{l}\text { Relative risk (95\% } \\
\text { CI) }\end{array}$ & $\begin{array}{l}\text { No who had } \\
\text { angiography* }\end{array}$ & $\begin{array}{l}\text { Patients with } \\
\text { events }\end{array}$ & Event rate & Relative risk (95\% Cl) \\
\hline \multicolumn{9}{|l|}{ Medium dose } \\
\hline \multicolumn{9}{|l|}{ Gavaghan ${ }^{42}$ : } \\
\hline Aspirin $324 \mathrm{mg}$ & 362 & 19 & 0.05 & \multirow{2}{*}{$\begin{array}{c}0.48 \\
(0.28 \text { to } 0.82)\end{array}$} & 119 & 14 & 0.12 & \multirow{2}{*}{$\begin{array}{c}0.39 \\
(0.22 \text { to } 0.70)\end{array}$} \\
\hline Placebo & 328 & 36 & 0.11 & & 100 & 30 & 0.30 & \\
\hline \multicolumn{9}{|l|}{ Goldman ${ }^{41}$ : } \\
\hline Aspirin 325 mg & 340 & 45 & 0.13 & \multirow{2}{*}{$\begin{array}{c}0.59 \\
(0.42 \text { to } 0.82)\end{array}$} & 104 & 36 & 0.35 & \multirow{2}{*}{$\begin{array}{c}0.79 \\
(0.56 \text { to } 1.11)\end{array}$} \\
\hline Placebo & 345 & 78 & 0.23 & & 107 & 47 & 0.44 & \\
\hline \multicolumn{9}{|l|}{ Low dose } \\
\hline \multicolumn{9}{|l|}{ Lorenz $^{40}$ : } \\
\hline Aspirin $100 \mathrm{mg}$ & 57 & 11 & 0.19 & \multirow{2}{*}{$\begin{array}{c}0.56 \\
(0.30 \text { to } 1.03)\end{array}$} & 29 & $6 \dagger$ & 0.27 & \multirow{2}{*}{$\begin{array}{c}0.44 \\
\text { (0.21 to } 0.92)\end{array}$} \\
\hline Placebo & 81 & 28 & 0.35 & & 31 & $15 \ddagger$ & 0.63 & \\
\hline \multicolumn{9}{|l|}{ Sanz ${ }^{43}$ : } \\
\hline Aspirin $150 \mathrm{mg}$ & 745 & 106 & 0.14 & \multirow{2}{*}{$\begin{array}{c}0.79 \\
(0.63 \text { to } 1.00)\end{array}$} & 373 & 101 & 0.27 & \multirow{2}{*}{$\begin{array}{c}0.82 \\
(0.66 \text { to } 1.03)\end{array}$} \\
\hline Placebo & 750 & 135 & 0.18 & & 371 & 122 & 0.33 & \\
\hline \multicolumn{9}{|l|}{ Hockings ${ }^{44}$ : } \\
\hline Aspirin $100 \mathrm{mg}$ & 128 & 6 & 0.05 & \multirow{2}{*}{$\begin{array}{c}0.52 \\
(0.20 \text { to } 1.34)\end{array}$} & 50 & 5 & 0.10 & \multirow{2}{*}{$\begin{array}{c}0.58 \\
(0.21 \text { to } 1.61)\end{array}$} \\
\hline Placebo & 145 & 13 & 0.09 & & 52 & 9 & 0.17 & \\
\hline
\end{tabular}

*Not all patients randomised underwent angiography.

$\dagger 6 / 22$ events reported.

$\ddagger 15 / 24$ events reported.

\section{Discussion}

No one likes prescribing any drug in a higher dose than is absolutely necessary to get the job done. The concept of a minimally effective dose of aspirin is attractive and is currently under evaluation for the prevention of stroke and myocardial infarction. ${ }^{45}$ However, limited evidence provided by five placebo controlled trials that randomised 1356 patients showed that medium rather than low dose regimens were more effective in reducing vein graft occlusion (risk ratio of $0.74 ; 0.52$ to 1.06 ) and event rates in patients $(0.81 ; 0.57$ to 1.16$)$. Although these results are not statistically significant, this possibility of a dose effect needs consideration; the wide confidence intervals reflect the scarcity of aspirin trials at these doses.

The best way to answer the question, of course, is by head to head comparison in a prospective randomised trial. Unfortunately, this has never been done. We therefore performed indirect comparison meta-analysis with placebo as an intermediary. This statistical technique does not replace randomised trials of direct comparison but is used to estimate treatment effect when direct comparative studies have not been performed ${ }^{5-7}$ or to strengthen the power of comparisons where few direct studies are available. $^{8}$

The validity of indirect comparison meta-analysis is built on the assumption that no important differences exist between trials examining medium or low dose regimens. If the two sets of trials differ with respect to a feature (clinical or methodological) that modified the treatment effect, then the comparisons of medium and low dose aspirin would be confounded. In our series, a notable difference was the shorter time to angiography in the low dose aspirin trials. In particular, this investigation was performed at a mean of 10 days (compared with one year in the medium dose trials) in the study by Sanz, the largest of the five trials. ${ }^{43}$ Although graft occlusion this early is often attributed to surgical technique ${ }^{46}$ a beneficial effect of aspirin compared with placebo on graft patency was already evident in this early time frame.

Although the indirect meta-analysis approach leads to greater uncertainty, it is clear that current evidence is inadequate to allow a definitive answer. Previous meta-analyses have shown that vascular graft patency is better with low to medium dose aspirin than with high dose regimes, but the possibility of differ- ing effects between the low and medium dose groups was not examined. ${ }^{45}$

\section{Clinical implications}

The financial implications of converting from low to medium dose therapy are marginal. Twenty $75 \mathrm{mg}$ tablets cost $£ 0.10$ $(\$ 0.17, € 0.15)$ and twenty $300 \mathrm{mg}$ tablets cost $£ 0.19(\$ 0.32$, $€ 0.28)$. Reluctance to convert to medium dose therapy is possibly due to concerns about bleeding, even though most postoperative prescription occurs on the first postoperative day, as the risk of bleeding is then reduced. ${ }^{47}$ A large prospective study of 5065 patients after coronary surgery reported a lower incidence of all bleeding complications in those who had received aspirin compared with patients who did not receive aspirin, ${ }^{48}$ thus supporting the safety of early postoperative aspirin administration. That is not to say that aspirin administration is without complications. Long term use is associated with established risks of bleeding. Recent meta-analyses, however, established that the proportional increase in major extracranial haemorrhage and gastrointestinal bleeding was not attenuated by using lower doses. ${ }^{49} 50$

Although it may be tempting to believe that low dose aspirin can attain a better safety profile while retaining therapeutic efficacy for graft patency, evidence to support either is limited. To take the argument further, what are the benefits of preventing graft occlusion? Angiographic follow up showed that death, myocardial infarction, and revascularisation rates were associated with the progression of vein graft disease. ${ }^{51}$ But the clinical picture is far from clear because comparative trials on aspirin therapy have not reported on survival, rates of recurrent angina, or need for a further operation that could potentially be altered by improved graft patency.

\section{Biological plausibility}

How does aspirin improve graft patency? It is generally accepted that aspirin is useful in the first month after surgery when vein graft attrition is caused mainly by thrombotic occlusion. ${ }^{48}$ Although low dose aspirin is sufficient to inhibit production of platelet thromboxane in patients with atherosclerosis, ${ }^{52}$ aggregometry after coronary bypass surgery showed that low dose aspirin $(100 \mathrm{mg})$ did not inhibit early postoperative platelet 


\section{What is already known on this topic}

Early use of aspirin after coronary surgery is safe and is associated with reduced risk of death and major vascular events

Low to medium dose aspirin $(75-325 \mathrm{mg}$ ) is equivalent or superior to high dose aspirin (500-1500 mg) in preventing vein graft occlusion

\section{What this study adds}

Compared with low dose aspirin regimens (75-150 mg), medium dose regimens $(300-325 \mathrm{mg})$ may be more effective in preventing graft occlusion and events in patients

aggregation. ${ }^{53}$ Why the biological effects of aspirin should be modified under these conditions is uncertain and may be due to the effects of cardiopulmonary bypass or surgical trauma. Similar comparative studies have not been performed to evaluate the biological effects at aspirin at higher doses. Later phases of intimal hyperplasia and vein graft arthrosclerosis are not influenced by aspirin therapy, ${ }^{54}$ and this is reflected by the attenuation of the beneficial effects on vein graft patency after the first year. ${ }^{38}$

If the antiplatelet action of aspirin is important for graft patency, further work is required to establish the optimum dosage for greatest biological effect and for it to be supported by trials with an emphasis on clinical outcome.

\section{Conclusions}

The results of our meta-analysis show that medium dose aspirin may more successfully reduce graft occlusion than low dose regimes within the first year after coronary surgery. With a proved safety profile in hospital, no substantial increase in cost, and no proportional increase in major haemorrhage, clinicians could consider $325 \mathrm{mg}$ as the optimum dose in the first year.

We thank Franco Ciulli for his support in the early stages of the preparation of this manuscript.

Contributors: EL had the original idea for the study, designed the study, abstracted data, drafted the manuscript, and is guarantor. ZA and AA carried out the data abstraction, designed the study, and assisted in drafting the manuscript. TR carried out data abstraction and assisted in drafting the manuscript. LE performed the literature search and assisted in drafting the manuscript. DGA performed the statistical analysis, designed the study, and drafted the manuscript. SL assisted in drafting the manuscript.

Funding: None.

Competing interests: None declared.

Ethical approval: Not required.

1 Keogh B, Kinsman R. National adult cardiac surgical database report 1999-2000. Berks: Dendrite Clinical Systems and The Society of Cardiothoracic Surgeons of Great Britain and Ireland, 2001.

2 Cooper GJ, Underwood MJ, Deverall PB. Arterial and venous conduits for coronary artery bypass. A current review. Eur I Cardiothorac Surg 1996;10:129-40.

3 Henderson WG, Goldman S, Copeland JG, Moritz TE, Harker LA. Antiplatelet or anticoagulant therapy after coronary artery bypass surgery. A meta-analysis of clinical trials. Ann Intern Med 1989;111:743-50.

4 Fremes SE, Levinton C, Naylor CD, Chen E, Christakis GT, Goldman BS. Optimal antithrombotic therapy following aortocoronary bypass: a meta-analysis. EurJ Cardiothora Surg 1993;7:169-80.

5 Collaborative overview of randomised trials of antiplatelet therapy - II: Maintenance of vascular graft or arterial patency by antiplatelet therapy. BMJ 1994;308:159-68.

6 Fisher LD, Gent M, Buller HR. Active-control trials: how would a new agent compare with placebo? A method illustrated with clopidogrel, aspirin, and placebo. Am Heart J 2001;141:26-32.

7 Packer M, Antonopoulos GV, Berlin JA, Chittams J, Konstam MA, Udelson JE Comparative effects of carvedilol and metoprolol on left ventricular ejection fraction in heart failure: results of a meta-analysis. Am Heart J 2001;141:899-907.

8 Song F, Glenny AM, Altman DG. Indirect comparison in evaluating relative efficacy illustrated by antimicrobial prophylaxis in colorectal surgery. Control Clin Trials 2000;21:488-97.
9 Bucher HC, Guyatt GH, Griffith LE, Walter SD. The results of direct and indirect treatment comparisons in meta-analysis of randomized controlled trials. J Clin Epidemiol 1997;50:683-91

10 Song F, Altman DG, Glenny AM, Deeks JJ. Validity of indirect comparison for estimating efficacy of competing interventions: empirical evidence from published meta-analyses. BMJ 2003;326:472.

11 Davey Smith G, Egger M. Going beyond the grand mean: subgroup analysis in metaanalysis of randomised trials. In: Altman DG, editor. Systematic reviews in heath care:metaanalysis in context. 2nd ed. London: BMJ Publishing, 2001:143-56.

12 Altman DG, Bland JM. Interaction revisited: the difference between two estimates. $B M J$ 2003;326:219.

13 Henderson WG, Moritz T, Goldman S, Copeland J, Souchek J, Zadina K, et al. The statistical analysis of graft patency data in a clinical trial of antiplatelet agents following coronary artery bypass grafting. Control Clin Trials 1988;9:189-205.

14 Mayer JE, Jr., Lindsay WG, Castaneda W, Nicoloff DM. Influence of aspirin and dipyridamole on patency of coronary artery bypass grafts. Ann Thorac Surg 1981;31:204-10.

15 McEnany MT, Salzman EW, Mundth ED, DeSanctis RW, Harthorne JW, Weintraub RM, et al. The effect of antithrombotic therapy on patency rates of saphenous vein coronary artery bypass grafts. J Thorac Cardiovasc Surg 1982;83:81-9.

16 Sharma GV, Khuri SF, Josa M, Folland ED, Parisi AF. The effect of antiplatelet therapy on saphenous vein coronary artery bypass graft patency. Circulation 1983;68:II218-21. 17 Brooks N, Wright J, Sturridge M, Pepper J, Magee P, Walesby R, et al. Randomised placebo controlled trial of aspirin and dipyridamole in the prevention of coronary vein graft occlusion. Br Heart J 1985;53:201-7.

18 Brown BG, Cukingnan RA, DeRouen T, Goede LV, Wong M, Fee HJ, et al. Improved graft patency in patients treated with platelet-inhibiting therapy after coronary bypass surgery. Circulation 1985;72:138-46.

19 Rajah SM, Salter MC, Donaldson DR, Subba Rao R, Boyle RM, Partridge JB, et al. Acetylsalicylic acid and dipyridamole improve the early patency of aorta-coronary bypass tylsalicylic acid and dipyriamole improve the early patency of aorta-coronary bypass
grafts. A double-blind, placebo-controlled, randomized trial. J Thorac Cardiovasc Surg grafts. A double

20 Pirk J, Vojacek J, Kovac J. Improvement of aortocoronary bypass patency by antiplatelet drug administration. Preliminary communication. Cor Vasa 1986;28:177-80.

21 Pirk J, Vojacek J, Kovac J, Fabian J, Firt P. Improved patency of the aortocoronary bypass by antithrombotic drugs. Ann Thorac Surg 1986;42:312-4.

22 Thaulow E, Froysaker T, Dale J, Vatne K. Failure of combined acetylsalicylic acid and dipyridamole to prevent occlusion of aortocoronary venous bypass graft. Scand J Thorac Cardiovasc Surg 1987;21:215-20.

23 Gershlick AH, Lyons JP, Wright JE, Sturridge MF, Layton CA, Balcon R. Long term clinical outcome of coronary surgery and assessment of the benefit obtained with postoperative aspirin and dipyridamole. Br Heart J 1988;60:111-6.

24 Rovelli F, Campolo L, Cataldo G, de Gaetano G, Lavezzari M, Mannucci PM, et al. Indobufen versus aspirin plus dipyridamole after coronary artery bypass surgery. Effects on graft patency 1 year after surgery. Circulation 1990;82(suppl III):III-507(A).

25 Rohn V, Pirk J, Mach T. The effect of indobufen on aortocoronary bypass patency after 1 week and after 1 year. (In Czech.) Cor Vasa 1993;35:162-4.

26 Rajah SM, Nair U, Rees M, Saunders N, Walker D, Williams G, et al. Effects of antiplatelet therapy with indobufen or aspirin-dipyridamole on graft patency one year after coronary artery bypass grafting. J Thorac Cardiovasc Surg 1994;107:1146-53.

27 Pantely GA, Goodnight SH, Jr., Rahimtoola SH, Harlan BJ, DeMots H, Calvin L, et al Failure of antiplatelet and anticoagulant therapy to improve patency of grafts after coronary-artery bypass: a controlled, randomized study. N Engl J Med 1979;301:962-6.

28 Chesebro JH, Clements IP, Fuster V, Elveback LR, Smith HC, Bardsley WT, et al. A platelet-inhibitor-drug trial in coronary-artery bypass operations: benefit of perioperative dipyridamole and aspirin therapy on early postoperative vein-graft patency. N Engl J Med 1982;307:73-8.

29 Chesebro JH, Fuster V, Elveback LR, Clements IP, Smith HC, Holmes DR Jr, et al. Effect of dipyridamole and aspirin on late vein-graft patency after coronary bypass operations. N Engl J Med 1984;310:209-14.

30 Guiteras P, Altimiras J, Aris A, Auge JM, Bassons T, Bonal J, et al. Prevention of aortocoronary vein-graft attrition with low-dose aspirin and triflusal, both associated with dipyridamole: a randomized, double- blind, placebo-controlled trial. Eur Heart J 1989;10:159-67.

31 Pfisterer M, Burkart F, Jockers G, Meyer B, Regenass S, Burckhardt D, et al. Trial of lowdose aspirin plus dipyridamole versus anticoagulants for prevention of aortocoronary vein graft occlusion. Lancet 1989;ii:1-7.

32 Yli-Mayry S, Huikuri HV, Korhonen UR, Airaksinen KE, Ikaheimo MJ, Linnaluoto MK, et al. Efficacy and safety of anticoagulant therapy started pre-operatively in preventing coronary vein graft occlusion. Eur Heart J 1992;13:1259-64.

33 Yamaguchi A, Kitamura N, Miki T, Tatebayashi T, Kawashima M, Otaki M, et al. Comparative study of anticoagulant management after coronary artery bypass surgery--warfarin versus dipyridamole. (In Japanese.) Nippon Kyobu Geka Gakkai Zasshi 1992;40:485-9.

34 Weber MA, Hasford J, Taillens C, Zitzmann A, Hahalis G, Seggewiss H, et al. Low-dose aspirin versus anticoagulants for prevention of coronary graft occlusion. Am J Cardiol 1990;66:1464-8.

35 Agnew TM, French JK, Neutze JM, Whitlock RM, Brandt PW, Kerr AR, et al. The role of dipyridamole in addition to low dose aspirin in the prevention of occlusion of coronary artery bypass grafts. Aust N Z J Med 1992;22:665-70.

36 Meister W, von Schacky C, Weber M, Lorenz R, Kotzur J, Reichart B, et al. Low-dose acetylsalicylic acid $(100 \mathrm{mg} /$ day) after aortocoronary bypass surgery: a placebocontrolled trial. Br J Clin Pharmacol 1984;17:703-11.

37 Goldman S, Copeland J, Moritz T, Henderson W, Zadina K, Ovitt T, et al. Improvement in early saphenous vein graft patency after coronary artery bypass surgery with antiplatelet therapy: results of a veterans administration cooperative study. Circulation 1988;77:1324-32.

38 Goldman S, Copeland J, Moritz T, Henderson W, Zadina K, Ovitt T, et al. Long-term graft patency (3 years) after coronary artery surgery. Effects of aspirin: results of a VA cooperative study. Circulation 1994;89:1138-43.

39 Cataldo G, Heiman F, Lavezzari M, Marubini E. Indobufen compared with aspirin and dipyridamole on graft patency after coronary artery bypass surgery: results of a combined analysis. Coron Artery Dis 1998;9:217-22. 
40 Lorenz RL, Schacky CV, Weber M, Meister W, Kotzur J, Reichardt B, et al. Improved aortocoronary bypass patency by low-dose aspirin $(100 \mathrm{mg}$ daily). Effects on platelet aggregation and thromboxane formation. Lancet 1984;i:1261-4

41 Goldman S, Copeland J, Moritz T, Henderson W, Zadina K, Ovitt T, et al. Saphenou vein graft patency 1 year after coronary artery bypass surgery and effects of antiplatelet therapy. Results of a veterans administration cooperative study. Circulation 1989;80:1190-7.

42 Gavaghan T, Gebski V, Baron D. Immediate postoperative aspirin improves vein graft patency early and late after coronary artery bypass graft surgery. A placebo-controlled, randomized study. Circulation 1991;83:1526-33.

43 Sanz G, Pajaron A, Alegria E, Coello I, Cardona M, Fournier J, et al. Prevention of early aortocoronary bypass occlusion by low-dose aspirin and dipyridamole. Grupo Espanol para el Seguimiento del Injerto Coronario (GESIC). Circulation 1990;82:765-73.

44 Hockings BE, Ireland MA, Gotch-Martin KF, Taylor RR. Placebo-controlled trial of enteric coated aspirin in coronary bypass graft patients. Effect on graft patency. Med J Aust 1993;159:376-8.

45 Patrono C, Coller B, Dalen JE, FitzGerald GA, Fuster V, Gent M, et al. Platelet-active drugs: the relationships among dose, effectiveness, and side effects. Chest 2001;119:S39-63.

46 Fuster V, Chesebro J. Role of platelets and platelet inhibitors in aortocoronary artery vein- graft disease. Circulation 1986;73:227-32.

47 Stein PD, Dalen JE, Goldman S, Theroux P. Antithrombotic therapy in patients with saphenous vein and internal mammary artery bypass grafts. Chest 1998;114(5 suppl):658-65S

48 Mangano DT. Aspirin and mortality from coronary bypass surgery. $N$ Engl J Med 2002;347:1309-17

49 Collaboration AT. Collaborative meta-analysis of randomised trials of antiplatelet therapy for prevention of death, myocardial infarction, and stroke in high risk patients. BMJ 2009.324:71-86

50 Derry S, Loke YK. Risk of gastrointestinal haemorrhage with long term use of aspirin: meta-analysis. BMJ 2000;321:1183-7.
51 Ellis SG, Brener SJ, DeLuca S, Tuzcu EM, Raymond RE, Whitlow PL, et al. Late myocardial ischemic events after saphenous vein graft intervention-importance of initially "nonsignificant" vein graft lesions. Am J Cardiol 1997;79:1460-4

52 Weksler BB, Pett SB, Alonso D, Richter RC, Stelzer P, Subramanian V, et al. Differential inhibition by aspirin of vascular and platelet prostaglandin synthesis in atherosclerotic patients. N Engl J Med 1983;308:800-5.

53 Zimmermann N, Kienzle P, Weber AA, Winter J, Gams E, Schror K, et al. Aspirin resistance after coronary artery bypass grafting. I Thorac Cardiovasc Surg 2001;121:982-4

54 Verstraete M, Brown BG, Chesebro JH, Fkestrom S, Harker LA, Henderson AH, et al. Evaluation of antiplatelet agents in the prevention of aorto-coronary bypass occlusion. Eur Heart J 1986;7:4-13.

(Accepted 30 September 2003)

bmj.com 2003;327:1309

Department of Cardiothoracic Surgery, Papworth Hospital, Cambridge CB3 8RE

Eric Lim specialist registrar in cardiothoracic surgery

Ziad Ali senior house officer in cardiothoracic surger

Ayyaz Ali clinical fellow in cardiothoracic surgery

Tom Routledge specialist registrar in cardiothoracic surgery

Stephen Large consultant cardiothoracic surgeon

Clinical Library Service, Papworth Hospital

Lyn Edmonds clinical library manager

Cancer Research UK/NHS Centre for Statistics in Medicine, Institute for Health Services, Oxford OX3 7LF

Douglas G Altman professor of statistics in medicine

Correspondence to: E Lim, Department of Cardiothoracic Surgery, Royal

Brompton Hospital, London SW3 6NP

eric.lim2@cvsnet.org 